\title{
Metal Oxide and Metal Complex Immobilization Modified Smectite Clay For Green Catalysis and Photo-Catalysis Applications: A Mini Review
}

\author{
Is Fatimah \\ Chemistry Department, Islamic University of Indonesia \\ Gedung FMIPA Lt.2, Kampus Terpadu UII J1. Kaliurang Km 14, Sleman, Yogyakarta, \\ Indonesia \\ Email: isfatimah@uii.ac.id
}

\begin{abstract}
Clay minerals are promising modifiable material for catalysis application. Fit to green chemistry issue, green catalysis based on clay minerals modification has been designed in our research group. Metal oxide and metal complexes modification onto natural and synthetic smectite clay via pillarization and intercalation processes and its application as green catalyst have been investigated. This paper presents the study on preparation of $\mathrm{Ni}, \mathrm{Zr}$ and $\mathrm{Pt}$ insertion on smectite clay structure for green conversion of citronellal to menthol via catalytic hydrogen transfer mechanism and Ru-complex modified smectite clay as novel photocatalysis application. Effect of clay structure modification was also studied in order to investigate the relationship between physicochemical characteristic change of material modifications and its catalytic/photo-catalytic activity. Some interesting phenomena related to the interaction of metal-clay support for their performance toward reaction kinetics and mechanism are reviewed, with emphasis on the evolution of surface properties and some factors affecting catalytic/photocatalytic activity.
\end{abstract}

Keywords: Photocatalyst; Clay; Smectitic clay; Pillarization; Intercalation, Photo-catalysis

\section{Introduction}

Green chemistry and green chemical engineering are the popular issues in recent years. Refer to twelve principles of green chemistry, a principle is related to catalysis and in other side it can be compromised with sustainability principle for sustainable development(Qi-xun et al., 2017)(Sir et al., 2013). Based on those reasons many researches focused and aimed to create and innovate a sustainable and regenerable catalyst for more efficient and effective processes in chemical industries. Utilization of natural mineral based catalysts is one scheme that can be developed and for these purposes clay and clay minerals have been intensively reported. Many publications are related to clay and clay modification for diverse applications, such as adsorbents in the bleaching of vegetable oils, drugs, catalysts, in the preparation of pillared clays, textiles, petroleum refining, etc. 
Within clay minerals classification itself, clay is devided by 2(two) categories; 1:1 layer and 2:1 layer structure. 1:1 layer structure consist of repeating units of tetrahedral and octahedral units, while the structure of a 2:1 is composed of repeating one octahedral unit is flanked by two layers of tetrahedral units. On the structure of the 1:1 one unit cell consists of six octahedral sides (four with cis orientation and two trans-oriented) and four tetrahedral sides, while in the structure of 2:1, the six sides will join the eight octahedral or tetrahedral sites(Kooli and Road, 1996). Between the interlayer spaces, there are exchangeable cations which neutralize the negative charges of main clay layers stucture. Schematic representation of smectite structure is presented in Figure1.

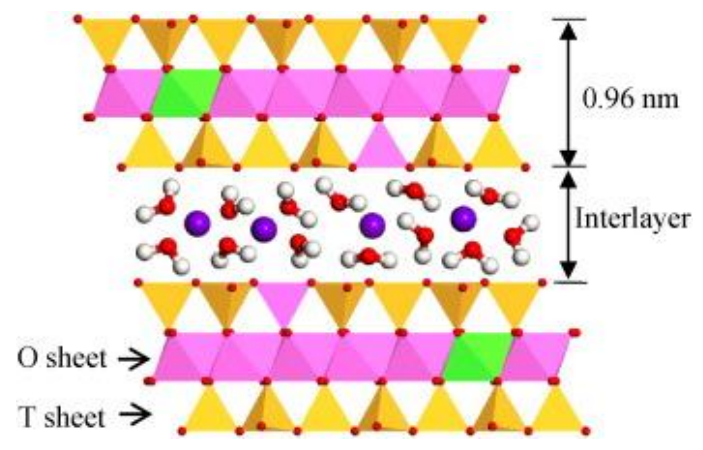

Figure 1. Schematic representation of smectite clay structure
By the presence of these cations, smectite clay can be chemically modified. Many attempts tailored surface and catalytic properties of clay minerals by inserting some metal and or metal oxide for suitable purposes. In accordance with the objectives of green chemistry and improved process efficiency, the use of modified clay for some organic synthesis is an attractive topic. In other side the synthesis of natural mineralbased catalyst can either reduce the production cost of the catalyst or participate in order to reduce waste production by the role of a heterogeneous catalyst(Gupta and Paul, 2014). On the basis of the large surface area owned clay theoretically increase in catalytic activity can be achieved. Such metal of $\mathrm{Pt}, \mathrm{Al}, \mathrm{Zr}, \mathrm{Zn}, \mathrm{Cu}$, $\mathrm{Cr}$ were reported to be actively increasing catalytic activity for organic reactions(Yang et al., 2002)(Vetere et al., 2002). Refer to some challenges in the field of synthesis of organic compounds important in the field of fragrance and pharmaceutical as well as in wastewater treatment, in this paper the scheme of clay modification related to catalytic application in eco-friendly organic synthesis and photocatalytic application is presented. From the basic idea that citronellal to isopulegol and menthol is an 
important platform and in other purpose water treatment over photocatalytic treatment is the popular work required for industry, the targeted organic reaction utilized to express the excellence activity of prepared materials is citronellal conversion to produce isopulegol and citronellal and for photocatalysis scheme a degradation reaction of bromophenol blue dye are utilized. By different mechanism and specific requirements of both reaction, we presents the synthesis of $\mathrm{Pt}, \mathrm{Ni}$ and $\mathrm{Zr}$ inserted onto smectite clay for citronellal conversion and Ruthenium-intercalated clay for photocatalytic degradation of bromophenol blue (BPB). Aims of study are related to study the effect of modification on physicochemical properties and catalytic activity.

Method

Natural montmorillonite (Mt) obtained from Pacitan, East Java was utilized as raw clay material and as comparison synthetic saponite(Sp) from Kuninime Industry, Japan was used. Some chemicals obtained from Sigma Aldrich consist of isopulegol, citronellal, menthol, and ruthenium complex and some other were purchased from Merck consist of isopropanol, $\quad \mathrm{H}_{2} \mathrm{PtCl}_{6}, \quad \mathrm{NiCl}_{2} \cdot 6 \mathrm{H}_{2} \mathrm{O}$, ammonium formate, bromophenol blue(BPB) and $\mathrm{ZrOCl}_{2} \cdot 2 \mathrm{H}_{2} \mathrm{O}$. Preparation of pillared clays: pillarization process is determined as two main steps: intercalation and calcination. The intercalation process of metal precursor was conducted by dispersing into clay suspension (5-10\%wt.) under stirring for a night followed by refluxing for $4 \mathrm{~h}$. The second step is calcination of intercalated clay after evaporation of solvent followed by drying. In this paper, pillared clays were prepared using of $\mathrm{Pt}, \mathrm{Ni}$ and $\mathrm{Zr}$ precursors with montmorillonite and saponite for citronellal conversion and for photocatalysis application $\operatorname{tris}\left(2,2^{\prime}-\right.$ bipyridyl)dichlororuthenium(II) hexahydrate $\left(\operatorname{Ru}(\mathrm{Bpy})_{3}\right)$ was utilized for intercalating agent. Produced materials are denoted as Metal-PILM and Metal-PILS for pillared and intercalated $\mathrm{Mt}$ and $\mathrm{Sp}$ respectively. Physicochemical character of materials were studied by instrumental analysis using x-ray diffraction(XRD), gas sorption analyser and SEM-EDX instrument. Catalytic activity test in citronellal conversion was engaged in a microwave assisted reaction method for 15 mins by using ammonium formate as catalytic hydrogen transfer agent. For photocatalytic oxidation, a batch reactor 
completed with UVA lamp 40 watt was employed.

\section{Result And Discussion}

\section{Material Characterization}

Intercalation and pillarization of clay structure is basically increase the interlayer space of clay structure from the inserted molecules. Identification on the success of the treatment can be identified from XRD measurement by $\mathrm{d}_{001}$ change/increasing.

Table 1. The $\mathrm{d}_{001}$ and FWHM of [001] reflection of the materials

\begin{tabular}{lll}
\hline Sample & $\mathbf{d}_{\mathbf{0 0 1}}(\AA)$ & FWHM(nm) \\
\hline $\mathrm{Mt}$ & 14.58 & 0.05 \\
$\mathrm{Sp}$ & 12.44 & 0.79 \\
$\mathrm{Zr}-\mathrm{PILM}$ & 16.50 & 0.44 \\
Zr-PILS & 14.60 & 0.54 \\
$\mathrm{Pt}-\mathrm{PILM}$ & 14.47 & 0.42 \\
$\mathrm{Pt}-\mathrm{PILS}$ & 12.54 & 0.043 \\
$\mathrm{Ni}-\mathrm{PILM}$ & 13.12 & 0.44 \\
$\mathrm{Ru}(\mathrm{Bpy})_{3} /$ Sap & 15.45 & 0.64 \\
& 13.56 & 0.69
\end{tabular}

Table 1 presents the change of $d_{001}$ of the materials after pillarization. From the data in the Table it is found that all pillarization creates higher $\mathrm{d}_{001}$ values. A specific case of
$\mathrm{Ru}(\mathrm{bpy}) 3$ intercalation it is found the double reflections for $\mathrm{d}_{001}$ indicating the possible conformation of inserted intercalating molecule within the structure. Increasing $\mathrm{d}_{001}$ as the result of metal attachment affects significantly to the surface acidity.

\section{Catalytic activity in citronellal conversion} In relationship with catalytic activity of the materials, Table 2 shows the calculated surface acidity based on n-butylammine adsorption and FTIR spectra by following equation:

Broensted to Lewis acid ratio $(\mathrm{L} / \mathrm{B})=$ $\frac{\text { Intensity of band at } 1450 \mathrm{~cm}-1}{\text { Intensity of band at } 1540 \mathrm{~cm}-1}$

From the catalytic mechanism (Figure 2), the total conversion (\%) and selectivity toward isopulegol and menthol are calculated by equation (2) and (3):

Conversion $\quad(\%) \quad=$
$\frac{[\text { initial conc.citronellal }]-[\text { conc.citronellal in sample }]}{[\text { initial conc.citronellal }]} \times 100 \%$

Selectivity to $-i(\%)=\frac{[\text { conc. } i]}{[\text { conc.products }]} \times 100 \%$ 
<smiles>CC(C)=CCCC(C)CC=O</smiles>

citronellal

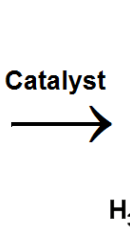

isopulegol

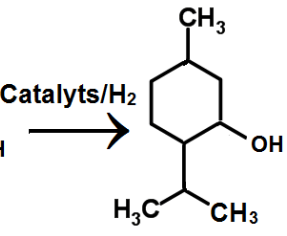

menthol

Figure 2. Catalytic steps of citronellal conversion

Table 2. L/B ratio, conversion and selectivity toward isopulegol and menthol

\begin{tabular}{lll}
\hline Catalyst & L/B & Conversion(\%) \\
& & \\
\hline Mt & 1.12 & 68.90 \\
Sap & 1.02 & 59.8 \\
Zr-PILM & 1.04 & 99.54 \\
Pt-PILM & 0.98 & 99.87 \\
Ni-PILM & 1.03 & 99.96 \\
Zr-PILS & 1.01 & 93.21 \\
Pt-PILS & 0.99 & 100.00 \\
Ni-PILS & 0.98 & 100.00 \\
\hline
\end{tabular}

Photocatalytic activity of Ru-(Bpy)3/Sap in $B P B$ degradation

Photocatalytic degradation of pollutant molecules from water and environment is an interesting technology refers to its low energy, renewable with minimum cost and less chemicals used

within the technology. Among some photocatalyst, $\mathrm{TiO}_{2}$ is the most popular material due to its high band gap energy $(3.2 \mathrm{eV})$ and less toxicity. However, innovation on the use alternative photocatalyst materials are widely developed in example efforts to use $\mathrm{ZnO}$ is intensively studied. Instead of some metal oxide photocatalyst, ruthenium complex is one of the important and potential photoactive compound for some photocatalytic reactions(Dirk et al., 2015; Hara et al., 2001; Ohno et al.,, 1999). ${ }^{\text {to }}$

$$
\text { insmelomal monthol }
$$

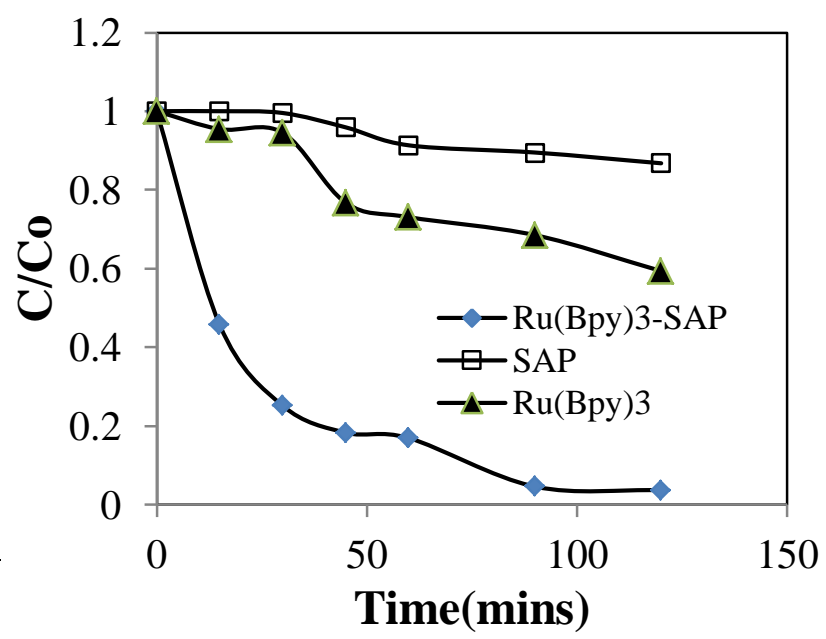

Figure 3. Kinetics of BPB degradation over baried catalyst

Related to the aim to stabilize photocatalytic activity, this research is dealing with ruthenium complex immobilization. From XRD results in Table 
1 it is confirmed that the immobilization was successfully created. Photocatalytic activity of the material is exhibited by kinetic curve in Figure 3. It is shown that immobilization improves the kinetics of BPB degradation. The contribution of porous structure is informed by specific surface area data in which $\mathrm{Ru}(\mathrm{Bpy})_{3} / \mathrm{Sap}$ give the specific surface area of $323.09 \mathrm{~m}^{2} / \mathrm{g}$ while raw Sap give $99.78 \mathrm{~m}^{2} / \mathrm{g}$.

\section{Conclusion}

It has been concluded from this study that the metal oxide immobilization in clay structure demonstrated the increasing surface parameter and activity in catalytic reaction. $\mathrm{Ni}, \mathrm{Pt}$ and $\mathrm{Zr}$ contribute to increase catalytic activity for citronellal conversion while $\mathrm{Ry}(\mathrm{Bpy})_{3} / \mathrm{Sap}$ verify the improving photocatalytic activity.

\section{References}

Dirk, A., M, Galhof., CB, Stark., M, Brasholz., 2015. Photoassisted oxidation of ruthenium(ii)photocatalysts $\mathrm{Ru}(\mathrm{bpy}) 3(2+)$ and $\mathrm{Ru}(\mathrm{bpz}) 3(2+)$ to $\mathrm{RuO} 4$ : orthogonal tandem photoredox and oxidation catalysis. Chem Commun (Camb). 52, 1025-1028.

Gupta, P., Paul, S., 2014. Solid acids: Green alternatives for acid catalysis. Catalysis Today. doi:10.1016/j.cattod.2014.04.010
Hara, M., Lean, J.T., Mallouk, T.E., 2001. Photocatalytic Oxidation of Water by Silica-Supported Sensitizers and Colloidal Iridium Oxide 4668-4675.

Kooli, F., Road, L., 1996. Ti-Pillared AcidActivated Clay Catalysts 4, 501-506.

Ohno, T., Tanigawa, F., Fujihara, K., Izumi, S., Matsumura, M., 1999. Photocatalytic oxidation of water by visible light using ruthenium-doped titanium dioxide powder. Journal of Photochemistry and Photobiology A: Chemistry 127, 107-110.

Qi-xun, S.H.I., Rong-wen, L. V, Zhu-xia, Z., De-feng, Z., 2017. AdvancQies in Heterogeneous Catalytic Transfer Hydrogenation of Aromatic Nitro Compounds 54-58.

Sir, B., Meurig, J., Press, I.C., 2013. Contributions to Green Chemistry , Clean Technology and Sustainability" 44-45.

Vetere, V., Santori, G.F., Moglioni, A., Moltrasio, G.Y., 2002. Hydrogenation of ( $\ddot{y})$-menthone, ( $\neq$ )-isomenthone, and ( $\ddagger)$-pulegone with platinum/tin catalysts 84 .

Yang, X., Jentoft, F.C., Jentoft, R.E., Girgsdies, F., Ressler, T., 2002. Sulfated zirconia with ordered mesopores as an active catalyst for $\mathrm{n}$ butane isomerization 2, 25-31. 